\title{
Effect of Soil Moisture Deficit Stress on Biomass Accumulation of Four Coffee (Coffea arabica) Varieties in Zimbabwe
}

\author{
Abel Chemura, ${ }^{1}$ Caleb Mahoya, ${ }^{2}$ Pardon Chidoko, ${ }^{2}$ and Dumisani Kutywayo ${ }^{3}$ \\ ${ }^{1}$ School of Agricultural Sciences and Technology, Chinhoyi University of Technology, Private Bag 7724, Chinhoyi, Zimbabwe \\ ${ }^{2}$ DR\&SS Coffee Research Institute, Chipinge, Zimbabwe \\ ${ }^{3}$ DR\&SS Head Office, Agricultural Research Centre, Harare, Zimbabwe
}

Correspondence should be addressed to Abel Chemura; achemura@gmail.com

Received 7 November 2013; Accepted 9 December 2013; Published 2 February 2014

Academic Editors: A. D. Arencibia and B. Kindiger

Copyright @ 2014 Abel Chemura et al. This is an open access article distributed under the Creative Commons Attribution License, which permits unrestricted use, distribution, and reproduction in any medium, provided the original work is properly cited.

\begin{abstract}
A study was conducted to evaluate four common coffee (Coffea arabica) varieties in Zimbabwe for drought tolerance and ability to recover. The plants were subjected to drought stress for 21 and 28 days with evaluation of recovery done 14 days after interruptive irrigation. Coffee varieties were not significantly different in initial fresh and dry biomass before stressing $(P>0.05)$. CR95 had significantly accumulated more $(P<0.05)$ dry root mass $(0.8 \mathrm{~g})$ than the rest of the varieties after 21 days of drought stress. SL28 and CR95 had an 8.3\% increase in dry biomass while Cat128 did not gain any dry biomass after 21 days of drought stress. CR95 had significantly more $(P<0.05)$ total dry biomass after 21 days and 28 days of drought stress while SL28 was consistently the least in both periods. Cat129 had the highest recovery gains in dry root, dry shoot, and total dry biomass after 21 days and 28 days of drought stress. Initial root biomass was negatively correlated with changes in total fresh and dry biomass of young coffee $(r>0.60)$ after both 21 and 28 days of drought stress, indicating that root biomass may be the most important factor determining drought tolerance in coffee varieties.
\end{abstract}

\section{Introduction}

Coffee (Coffea arabica) is produced in many developing countries contributing significantly to poverty alleviation and national economic development. In addition to the importance of coffee in many African national economies in terms of GDP and export earnings, it is directly linked to poverty alleviation as the majority of producers are smallholder farmers, and many rely only on coffee for socioeconomic development $[1,2]$. The majority of the coffee produced in Southern Africa is Arabica coffee (Coffea arabica L.) which requires well-distributed rainfalls totaling over $1000 \mathrm{~mm}$ per year and temperatures between 24 and $26^{\circ} \mathrm{C}$ [35]. In Zimbabwe, coffee is produced in the eastern highlands districts of Chipinge, Chimanimani, Mutare, and Mutasa where natural climatic conditions approximate requirements and in the northern parts of the country in Guruve, Harare, and Mhangura districts under managed conditions $[6,7]$.
Coffee is a unique and legal source of income for many smallholder farmers and, as such, production has expanded from traditional areas to marginal areas where meeting crop water requirement is a serious challenge. In addition, in traditional production areas rainfall patterns have become unpredictable and unreliable exposing the coffee plants to frequent and often severe droughts $[8,9]$. Changing weather patterns due to climate change and variability are projected to reduce the suitability of areas under coffee production in many producing zones, increase the risk of coffee pests and diseases, and increase coffee production costs [7, 9-13].

Soil moisture stress due to drought limits production through inhibiting growth and causing plant wilting and dieback. These in turn reduce yields and quality and expose the plant to opportunistic pathogens and pests [14-16]. Coffee production faces heightened risk of droughts because coffee is a perennial crop that is in the field throughout the year 
$[10,17]$. The major abiotic stresses that are projected to be increased by a changing climate are droughts, heat, salinization, water logging, pest, and disease epidemics [18]. The impact of droughts is more pronounced on the smallholder coffee sector that often relies on rainfed systems and lack both alternatives and coping options. Studies have indicated that coffee performs better under irrigation than under rainfed conditions $[6,16,19]$. Irrigation is therefore becoming a necessity for successful coffee production in many areas. However, even in areas where a reliable source of good quality water supply can be secured, irrigation comes with increased costs of installation, water pumping, and maintenance which reduces profitability of coffee production and makes it out of reach for many resource constrained smallholder farmers.

Among the most promising adaptation options is genetic improvement for development of crop varieties that can maintain productivity under less than optimal climatic conditions [10, 20]. According to DaMatta et al. [21], mechanisms involved in plant drought tolerance are drought avoidance, dehydration tolerance, and dehydration postponement. These are achieved through physiological adjustments, morphological change, changing resource allocation, and altering biochemical components of the plant system in response to moisture deficit and other environmental stresses [14, 22, 23]. The physiological responses of the coffee plant include leaf folding, leaf and branch dieback, and leaf shape change [24]. Biomass allocation between the roots, the stems, and leaves of the plant could be changed as a plant adjusts to moisture stress, optimizing the available moisture resources to the most important systems for survival $[24,25]$.

Development of deep roots to increase the soil water catchment and biophysical control of water loss through reducing leaf area and closure of stoma can be used by the plant to maintain a positive plant water status [21]. For example, the rates and direction of root growth of plants are principally determined by soil water gradients [4]. In addition, osmotic adjustment such as increasing net solute concentration significantly contributes to turgor maintenance thereby necessitating metabolic processes such as photosynthesis, growth, and in some plants reproduction and seed dispersal [26]. Maintaining turgor especially in the leaves can also be attained by increases in tissue elasticity. Increasing tissue elasticity results in attainment of a low water potential without the plant experiencing the detrimental effects of water deficit $[8,21,26]$. These characteristics vary between plant species and varieties [27]. The ability of a crop or crop variety to achieve these and other related water use and water retention characteristics enables it to be regarded as drought tolerant. Drought tolerant varieties are suitable for a wide range of agroecological environments and reduce irrigation requirements and associated costs.

To complement genetic improvement efforts, it is necessary to take stock of current germplasm in terms of drought tolerance in order to inform future breeding and selection programs. In Zimbabwe, there are many formally and informally introduced coffee genetic materials that have not been adequately evaluated. This limits the potential use of these materials in breeding programs and in crop production. There has been very limited deliberate research to assess the drought tolerance of coffee varieties under production, many of which have been primarily developed focusing on disease tolerance. In addition, an understanding of the yield differences between these varieties under different environments and management practices could be obtained from their physiological response to soil moisture deficit stress. The objectives of this study were to evaluate the morphological response of different coffee varieties under moisture deficit stress and determine the initial physiological characteristics that are related to resilience.

\section{Materials and Methods}

2.1. Study Site. The trial was carried out in the greenhouse at Coffee Research Institute (CoRI) between November and December 2012. CoRI is located at $20^{\circ} 12 \mathrm{~S}$ and $32^{\circ} 37 \mathrm{E}$ at an altitude of 1100 m.a.s.l [28]. The average annual rainfall is $1180 \mathrm{~mm}$ of which $80 \%$ falls in five months from November to March. The mean maximum temperature is $20^{\circ} \mathrm{C}$ and minimum is $14^{\circ} \mathrm{C}$. Most of the soils in this area are leached and strongly weathered and in the orthoferralitic group derived from Umkondo quartzites and sandstone [29].

2.2. Experimental Materials and Design. Four varieties were assessed for their response to moisture deficit stress. These were SL28, Costa Rica 95 (CR95), Catimor 128, and Catimor 129. Seedlings of these varieties were grown in the nursery in recommended growth medium for raising coffee seedlings in black polythene pots. Watering was done on a weekly interval and all other routine nursery management activities were based on nursery recommendations from the Coffee Handbook [4]. Eight-month-old seedlings were subjected to two moisture stress regimes, one for 21 days and the other for 28 days from November 14, 2012, under greenhouse conditions to protect them from rain. After moisture stress period, the seedlings were irrigated and assessed for their recovery ability with biomass measurements after 2 weeks. For each variety and each assessment (initial, 21 days, 28 days, 21 days, 14 days recovery and 28 days and 14 days recovery) three coffee plants were used. The trial was laid out in a Complete Randomized Design.

2.3. Measurements and Data Analysis. Destructive sampling was done to weigh the roots, shoots, and total biomass. The roots were carefully excavated and cleaned with tap water before being weighed. The fresh and oven-dried $\left(70^{\circ} \mathrm{C}\right.$ for $8 \mathrm{hrs}$ ) mass of roots shoots and total biomass were measured using a digital balance. Data were analyzed using analysis of variance (ANOVA) and Pearson correlation was used to determine the correlation between initial biomass and changes in biomass after soil moisture deficit stress in $\mathrm{R}$ Statistical Software [30].

\section{Results}

3.1. Root Biomass. Varieties did not show significant differences $(P>0.05)$ in root biomass before stressing (Table 1$)$. There were significant differences in dry root biomass after 21 
TABLE 1: Root biomass of coffee seedlings before, and after stressing and after recovery.

\begin{tabular}{|c|c|c|c|c|c|c|c|c|c|c|}
\hline \multirow{2}{*}{ Variety } & \multicolumn{2}{|c|}{ Initial } & \multicolumn{2}{|c|}{21 days } & \multicolumn{2}{|c|}{28 days } & \multicolumn{2}{|c|}{$21+14$ days } & \multicolumn{2}{|c|}{$28+14$ days } \\
\hline & Fresh & Dry & Fresh & Dry & Fresh & Dry & Fresh & Dry & Fresh & Dry \\
\hline SL28 & 1.8 & 0.4 & 1.8 & $0.4^{\mathrm{a}}$ & $1.4^{\mathrm{a}}$ & $0.4^{\mathrm{a}}$ & $1.6^{\mathrm{a}}$ & 0.4 & 2.8 & 0.5 \\
\hline Cat129 & 2.3 & 0.4 & 2.3 & $0.5^{\mathrm{ab}}$ & $1.8^{\mathrm{a}}$ & $0.5^{\mathrm{a}}$ & $1.9^{\mathrm{ab}}$ & 0.5 & 3.6 & 0.7 \\
\hline Cat128 & 2.0 & 0.5 & 1.8 & $0.5^{\mathrm{ab}}$ & $1.7^{\mathrm{a}}$ & $0.6^{\mathrm{a}}$ & $2.1^{\mathrm{ab}}$ & 0.6 & 2.2 & 0.5 \\
\hline CR95 & 3.4 & 0.7 & 3.4 & $0.8^{\mathrm{b}}$ & $5.0^{\mathrm{b}}$ & $0.9^{\mathrm{b}}$ & $3.6^{\mathrm{b}}$ & 0.9 & 5.1 & 0.9 \\
\hline$P$ & 0.167 & 0.099 & 0.338 & 0.025 & 0.007 & 0.004 & 0.042 & 0.119 & 0.171 & 0.442 \\
\hline
\end{tabular}

Means with the same letter within a column are not significantly different according to Tukey's test $(P=0.05)$.
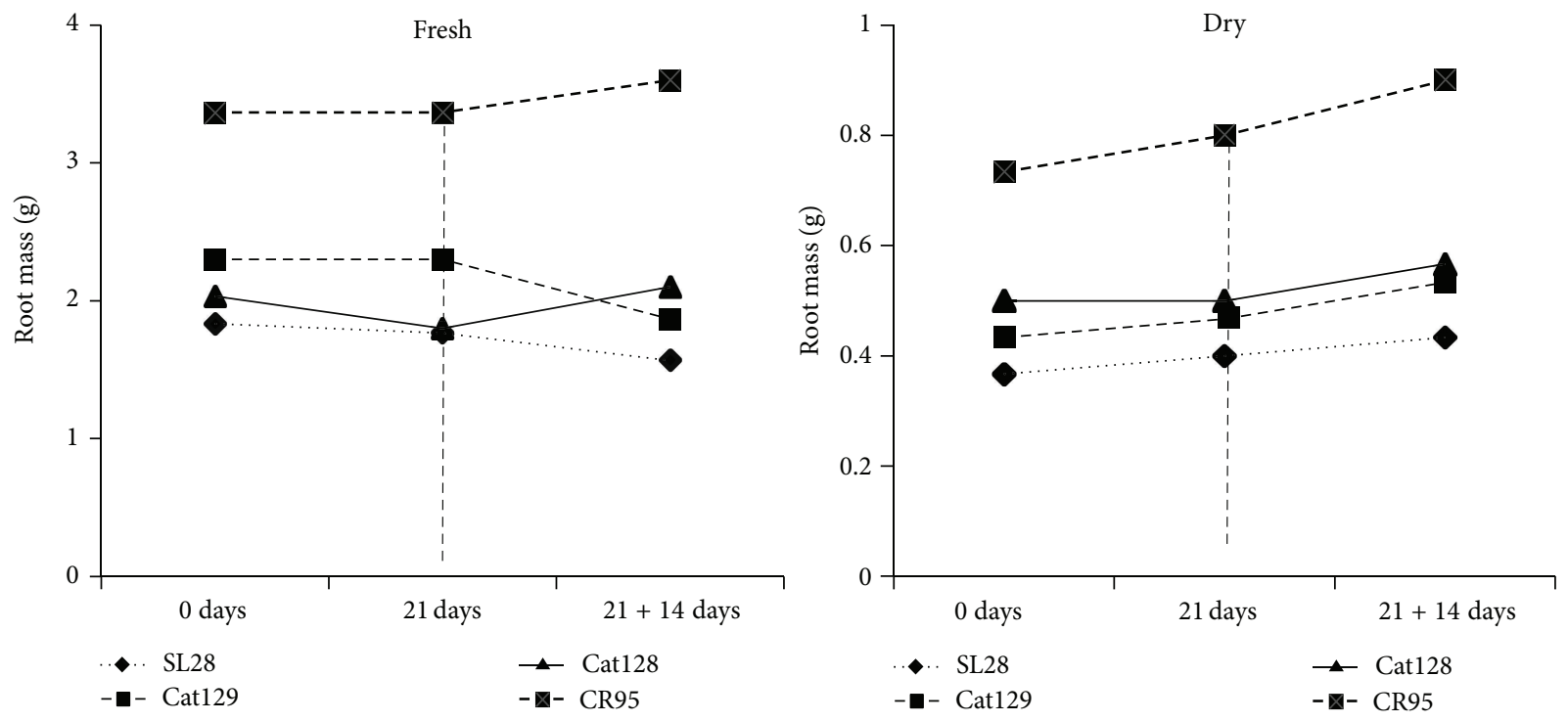

(a)
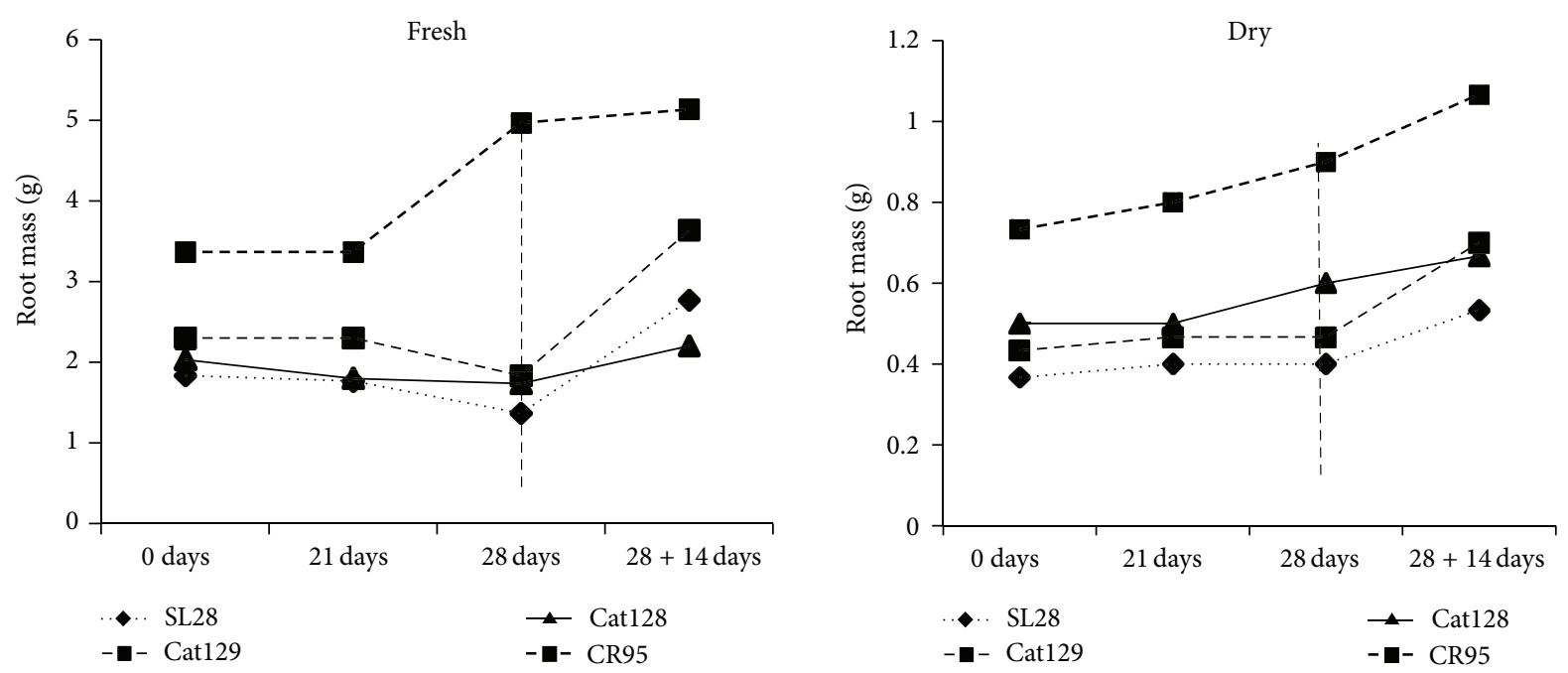

(b)

FIGURE 1: Changes in fresh and dry root biomass after stressing and recovery (a broken line indicates the time of interruptive irrigation).

days of moisture stress $(P<0.05)$. CR95 had the heaviest root mass $(0.8 \mathrm{~g})$ while SL28 had the least mass $(0.4 \mathrm{~g})$. After 28 days of soil moisture stress, there were significant differences in fresh and dry root biomass between varieties $(P<0.05)$. CR95 had higher fresh and dry biomass ( $5 \mathrm{~g}$ and $0.9 \mathrm{~g}$, resp.) than the rest of the varieties which were not significantly different from each other (Table 1).

Fresh root biomass was significantly different $(P<0.05)$ after 21 days of stressing and 14 days of recovery while dry biomass was not significantly different after the same period 
TABLE 2: Percentage changes in root biomass after 21 and 28 days of stressing and recovery.

\begin{tabular}{lccccccrc}
\hline Roots & \multicolumn{2}{c}{21 days } & \multicolumn{2}{c}{28 days } & \multicolumn{2}{c}{$21+14$ days } & \multicolumn{2}{c}{$28+14$ days } \\
variety & Fresh & Dry & Fresh & Dry & Fresh & Dry & Fresh \\
\hline SL28 & -3.8 & 8.3 & -34.1 & 8.3 & -11.3 & 8.3 & 102.4 \\
Cat129 & 0.0 & 7.1 & -25.5 & 7.1 & -18.8 & 14.3 & 98.2 \\
Cat128 & -13.0 & 0.0 & -17.3 & 16.7 & 16.7 & 13.3 & 26.9 & 50.0 \\
CR95 & 0.0 & 8.3 & 32.2 & 18.5 & 6.9 & 12.5 & 3.4 \\
\hline
\end{tabular}
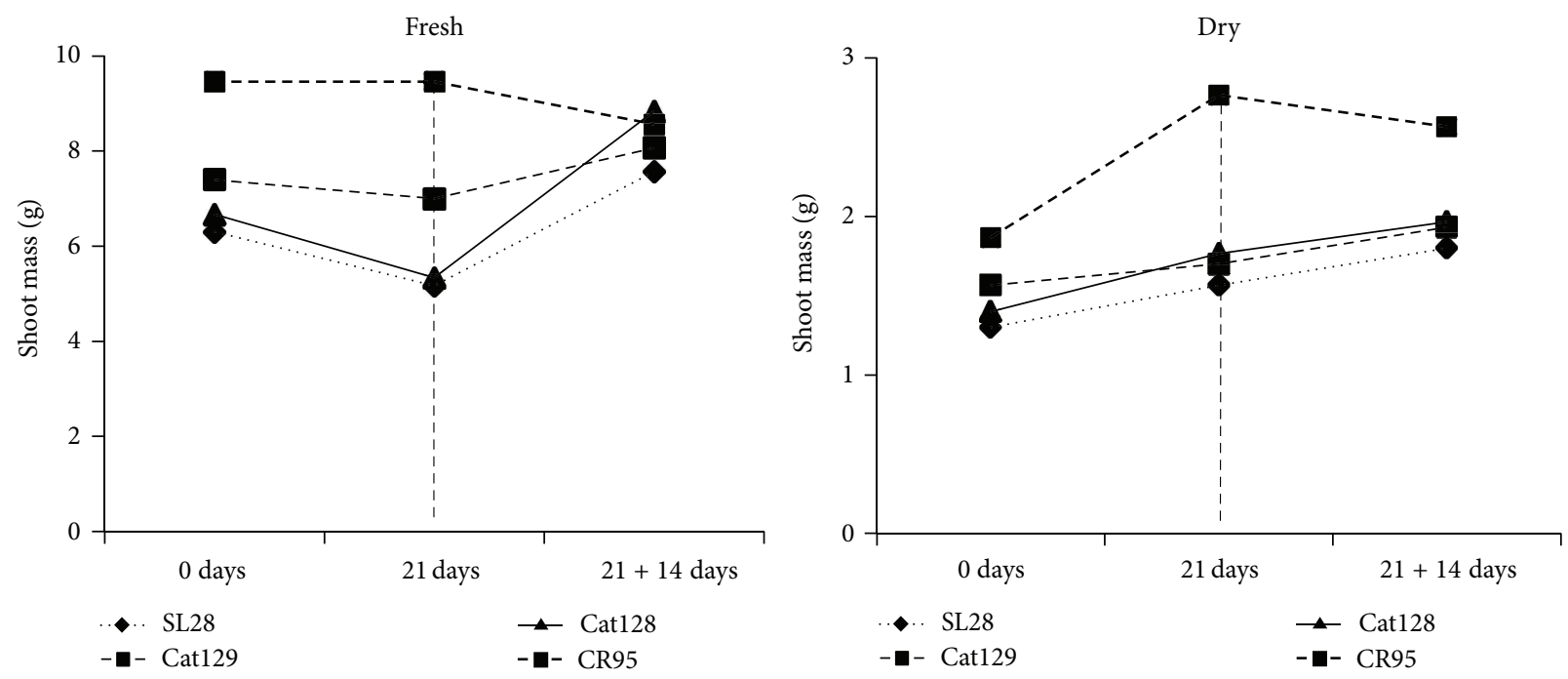

(a)
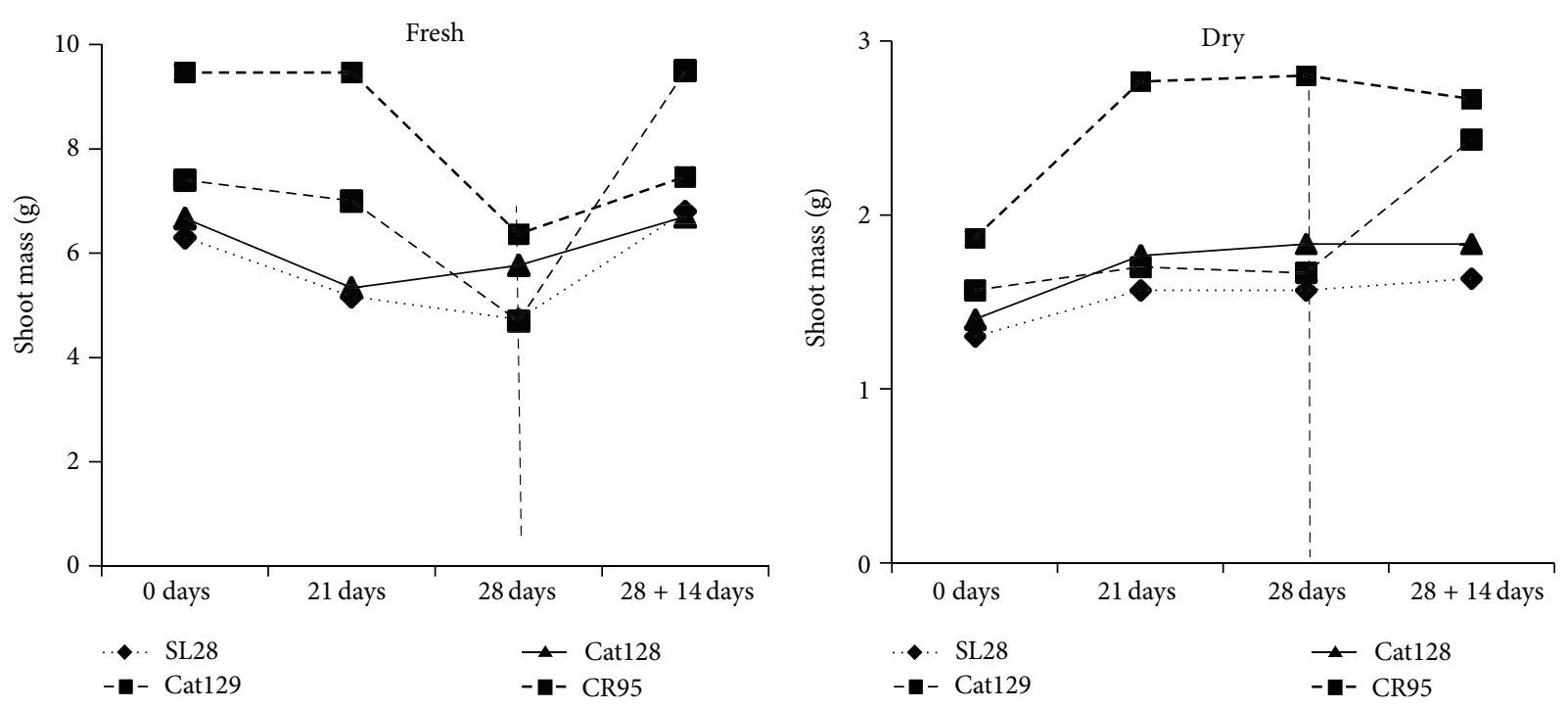

(b)

FIGURE 2: Changes in fresh and dry shoot biomass after stressing and recovery (dashed line shows time of interruptive irrigation application).

$(P>0.05)$. No significant differences $(P>0.05)$ were realized between varieties after 28 days of stressing and 14 days of recovery. The highest change in fresh biomass after 21 days of moisture stress was for Cat128 which lost $13 \%$ followed by SL28 which lost 3.8 of fresh weight (Table 2).

There were no changes in fresh weight in Cat129 and CR95. In terms of dry weight, Cat128 did not show any change after 21 days of soil moisture stress while SL28 and CR95 gained 8.3\% of dry biomass during the same period. After 28 days of soil moisture stress, only CR95 had positive change in fresh root biomass (32.2\%). Although CR95 had significantly heavier dry root biomass than the rest of the varieties, its percentage gain in dry root biomass after 21 days of soil moisture stress was the same as that of SL28 (Table 2). 
TABLE 3: Shoot biomass of coffee seedlings before, and after stressing and after recovery.

\begin{tabular}{lcccccccccc}
\hline Shoots & \multicolumn{2}{c}{ Initial } & \multicolumn{2}{c}{ 21 days } & \multicolumn{2}{c}{28 days } & \multicolumn{2}{c}{$21+14$ days } & \multicolumn{2}{c}{$28+14$ days } \\
variety & Fresh & Dry & Fresh & Dry & Fresh & Dry & Fresh & Dry & Fresh & Dry \\
\hline SL28 & 6.3 & 1.3 & 5.2 & 1.6 & 4.7 & $1.6^{\mathrm{a}}$ & 7.6 & 1.8 & 6.8 \\
Cat129 & 7.4 & 1.6 & 7.0 & 1.7 & 4.7 & $1.7^{\mathrm{a}}$ & 8.1 & 1.9 & 9.5 \\
Cat128 & 6.7 & 1.4 & 5.3 & 1.8 & 5.8 & $1.8^{\mathrm{a}}$ & 8.8 & 2.0 & 6.7 & 2.4 \\
CR95 & 9.5 & 1.9 & 9.5 & 3.4 & 6.4 & $2.8^{\mathrm{b}}$ & 8.6 & 2.6 & 7.5 & 2.4 \\
\hline$P$ & 0.465 & 0.398 & 0.255 & 0.094 & 0.351 & 0.009 & 0.836 & 0.344 & 0.764 & 0.311 \\
\hline
\end{tabular}

Means with the same letter within a column are not significantly different according to Tukey's test $(P=0.05)$.
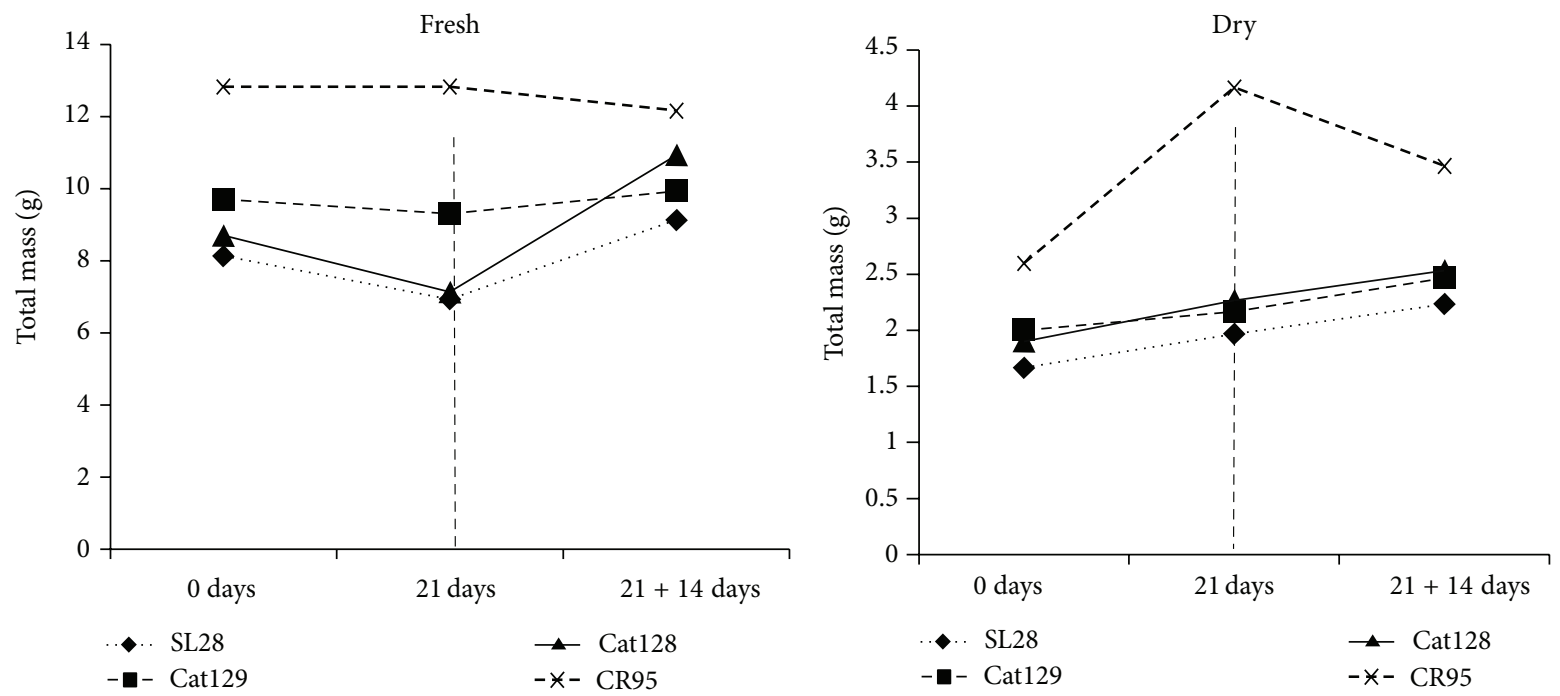

(a)
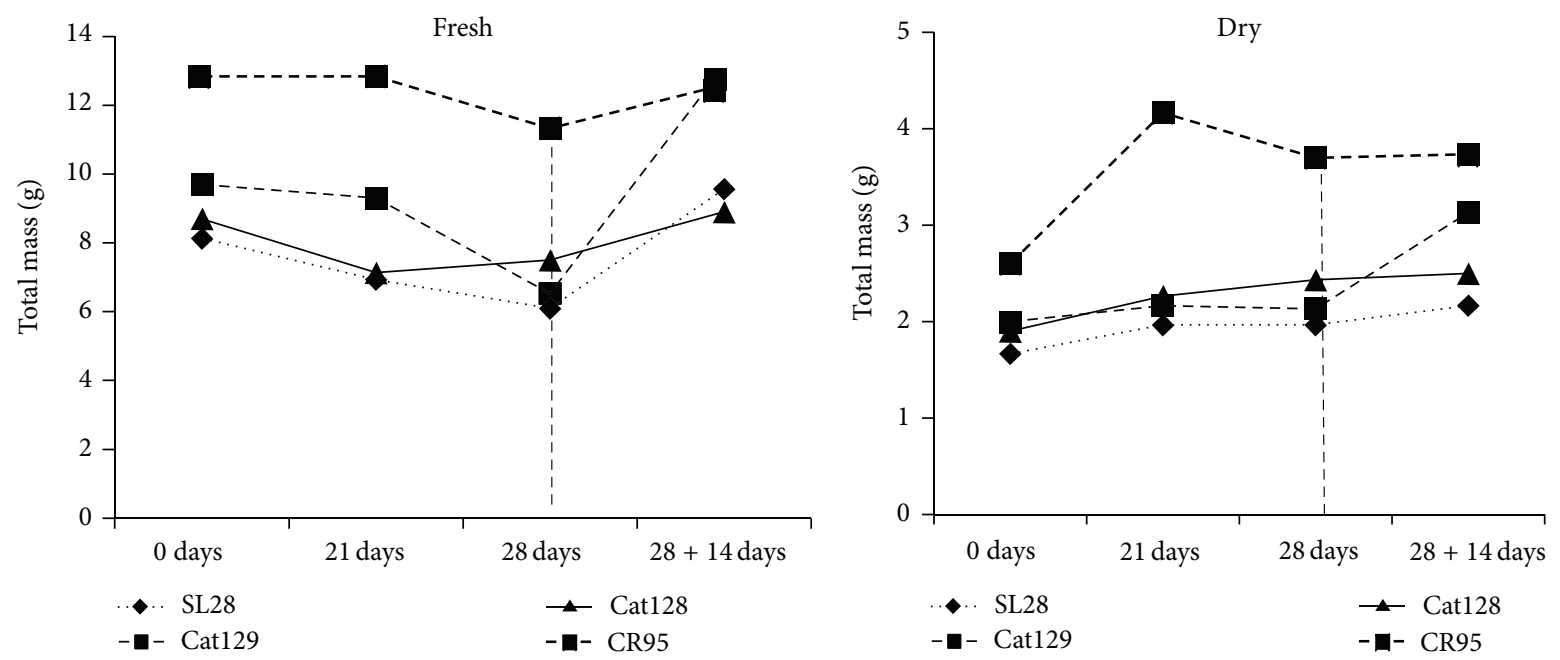

(b)

FIGURE 3: Changes in total fresh and dry biomass after stressing and recovery (dashed line shows time of interruptive irrigation application).

TABLE 4: Percentage changes in shoot biomass after 21 and 28 days of stressing and recovery.

\begin{tabular}{lcccccccc}
\hline Shoots & \multicolumn{2}{c}{21 days } & \multicolumn{2}{c}{28 days } & \multicolumn{2}{c}{$21+14$ days } & \multicolumn{2}{c}{$28+14$ days } \\
variety & Fresh & Dry & Fresh & Dry & Fresh & Dry & Fresh \\
\hline SL28 & -21.9 & 17.0 & -33.1 & 17.0 & 46.5 & 14.9 & 43.7 \\
Cat129 & -5.7 & 7.8 & -57.4 & 6.0 & 15.2 & 13.7 & 102.1 \\
Cat128 & -25.0 & 20.8 & -15.6 & 23.6 & 65.6 & 11.3 & 16.2 \\
CR95 & 0.0 & 32.5 & -48.7 & 33.3 & -9.5 & -7.2 & 16.0 \\
\hline
\end{tabular}


TABLE 5: Total plant biomass before stressing, after stressing, and after recovery.

\begin{tabular}{|c|c|c|c|c|c|c|c|c|c|c|}
\hline \multirow{2}{*}{$\begin{array}{l}\text { Total } \\
\text { variety }\end{array}$} & \multicolumn{2}{|c|}{ Initial } & \multicolumn{2}{|c|}{21 days } & \multicolumn{2}{|c|}{28 days } & \multicolumn{2}{|c|}{$21+14$ days } & \multicolumn{2}{|c|}{$28+14$ days } \\
\hline & Fresh & Dry & Fresh & Dry & Fresh & Dry & Fresh & Dry & Fresh & Dry \\
\hline SL28 & 8.1 & 1.7 & 6.9 & $2.0^{\mathrm{a}}$ & $6.1^{\mathrm{a}}$ & $2.0^{\mathrm{a}}$ & 9.1 & 2.2 & 9.6 & 2.2 \\
\hline Cat129 & 9.7 & 2.0 & 9.3 & $2.2^{\mathrm{ab}}$ & $6.5^{\mathrm{ab}}$ & $2.1^{\mathrm{a}}$ & 9.9 & 2.5 & 13.1 & 3.1 \\
\hline Cat128 & 8.7 & 1.9 & 7.1 & $2.3^{\mathrm{ab}}$ & $7.5^{\mathrm{ab}}$ & $2.4^{\mathrm{a}}$ & 10.9 & 2.5 & 8.9 & 2.0 \\
\hline CR95 & 12.8 & 2.6 & 12.8 & $4.2^{\mathrm{b}}$ & $11.3^{\mathrm{b}}$ & $3.7^{\mathrm{b}}$ & 12.2 & 3.5 & 12.6 & 3.3 \\
\hline$P$ & 0.327 & 0.23 & 0.246 & 0.038 & 0.037 & $<0.001$ & 0.379 & 0.123 & 0.661 & 0.36 \\
\hline
\end{tabular}

Means with the same letter within a column are not significantly different according to Tukey's test $(P=0.05)$.

TABLE 6: Percentage changes in total biomass after 21 and 28 days of stressing and recovery.

\begin{tabular}{lccccccc}
\hline Total & \multicolumn{2}{c}{21 days } & \multicolumn{2}{c}{28 days } & \multicolumn{2}{c}{$21+14$ days } & \multicolumn{2}{c}{$28+14$ days } \\
variety & Fresh & Dry & Fresh & Dry & Fresh & Dry & Fresh \\
\hline SL28 & -17.3 & 15.3 & -33.3 & 15.3 & 31.7 & 13.6 & 56.8 \\
Cat129 & -4.3 & 7.7 & -48.5 & 6.3 & 6.8 & 13.8 & 101.0 \\
Cat128 & -22.0 & 16.2 & -16.0 & 21.9 & 53.3 & 11.8 & 18.7 \\
CR95 & 0.0 & 37.6 & -13.2 & 29.7 & -5.2 & -16.8 & 11.2 \\
\hline
\end{tabular}

The greatest loss in fresh root biomass was for SL28 which lost $34.1 \%$. CR95 gained $18.5 \%$ of dry root biomass after 28 days of soil moisture stress. Corresponding to the losses in fresh root biomass, SL28 and Cat129 had the least increase in dry biomass after 28 days of stressing, gaining $8.3 \%$ and $7.1 \%$ dry root biomass. These varieties (SL28 and Cat129) continued to lose fresh biomass during the 14 days recovery period after 21 days moisture stress. Cat128 gained the highest percentage of fresh root biomass while Cat129 gained the highest amount of dry biomass during this recovery period.

When the coffee plants were irrigated for 14 days after a 28-day stressing period, SL28 and Cat129 had the highest percentage increases in fresh root biomass $(102.4 \%$ and $98.2 \%$, resp.). The least gain in fresh root biomass was for CR95 which only increased fresh biomass by $3.4 \%$. The highest percentage increase in dry root biomass was for Cat129 whose dry root biomass increased by $50 \%$ (Figure 1). In terms of fresh root biomass, Cat128 had the most gains after 21 days of soil moisture stress while SL28 and Cat129 had the highest gain in fresh root biomass after 28 days of soil moisture stress.

3.2. Shoot Biomass. Fresh and dry shoot biomass did not significantly differ between varieties before and after 21 days of soil moisture stress $(P>0.05)$. CR95 had superior $(P<$ $0.05)$ shoot dry biomass than other varieties after 28 days of soil moisture stress (Table 3 ). There were no significant differences in shoot biomass between varieties after both recovery periods $(P>0.05)$.

SL28, Cat129, and Cat128 lost fresh shoot biomass after 21 days of soil moisture stress. There was no change in fresh shoot biomass for CR95. CR95 had the highest percentage change in dry shoot biomass, gaining $32.5 \%$ during the 21 days soil moisture stressing period (Table 4). The least percentage change in shoot biomass was for Cat128 which gained $7.8 \%$ of dry biomass after 21 days stressing period. After 28 days of soil moisture stress, all varieties had lost fresh shoot biomass with the greatest loss shown by Cat129 (57.4\%) followed CR95 (48.7\%).

Corresponding to the greatest fresh shoot biomass losses, Cat129 had the least gains in dry shoot biomass after 28 days of soil moisture stress (6\%) compared to CR95 which gained $33.3 \%$ of dry biomass during the same period. Interestingly, unlike other varieties, CR95 lost both fresh and dry biomass during recovery from 21 days of soil moisture stress while Cat128 and SL28 had big percentage gains in fresh shoot biomass (65.6\% and $46.5 \%$, resp.) during the same period. During recovery from 28 days of soil moisture stress, Cat129 had the highest percentage gains in fresh and dry shoot biomass while CR95 had an increase of $17.3 \%$ in fresh biomass but suffered a loss of 7.3 in dry shoot biomass (Figure 2).

3.3. Total Biomass. Initial fresh and dry biomass was not significantly different between varieties $(P>0.05)$. CR95 had significantly $(P<0.05)$ more total dry biomass after 21 days of soil moisture stress. Significantly more biomass $(P<0.05)$ was also realized from CR95 after 28 days of soil moisture stress with SL28 consistently being the least in both (Table 5). However, there were no significant differences $(P>0.05)$ in fresh and dry biomass between SL28, Cat129, and Cat128. Varieties did not show any significant differences $(P>0.05)$ in fresh and dry biomass 2 weeks after application of irrigation after both 21 days and 28 days of soil moisture stress (Table 5).

All varieties except CR95 had a reduction in total fresh biomass after 21 days of soil moisture stress. CR95 increased in total dry biomass by $37.6 \%$ and $29.7 \%$ after 21 days and 28 days of soil moisture stress respectively. Contrary, Cat129 gained only $7.7 \%$ and $6.3 \%$ of total biomass after 21 days and 28 days of soil moisture stress (Table 6). There were no changes in total fresh biomass of CR95 after 21 days of soil 
moisture stress, but after 28 days, the variety had lost 13.2\% of fresh biomass.

CR95 continued to lose both fresh $(-16.8 \%)$ and dry $(-5.2 \%)$ biomass into the 2 weeks recovery after 21 days of soil moisture stress. During the same period, other varieties had increases in both fresh and dry biomass. Cat128 gained the most total fresh biomass (53.3\%) while SL28 and Cat129 had the highest gains in total dry biomass $(13.6 \%$ and $13.8 \%$, resp.).

The greatest recovery potential after 28 days of soil moisture stress was shown by Cat129 which gained $101.0 \%$ of total fresh biomass and $46.9 \%$ of total dry biomass (Figure 3 ). CR95 was the least gaining only $11.2 \%$ of its total fresh biomass and $0.9 \%$ of its total dry biomass in the same period. Cat129 had the highest gains in dry root, shoot, and total biomass after 21 days and 28 days of soil moisture stress followed by SL28.

\subsection{Correlation between Initial Biomass and Change after} Stress. There was a strong positive relationship between a variety's initial fresh root biomass and changes in fresh root biomass $(r=0.855)$, dry root biomass $(r=0.788)$, and fresh and dry total biomass ( $r=0.83$ and $r=0.912$, resp.) after 21 days of soil moisture deficit stress (Table 7).

After 21 days of soil moisture deficit stress, the strongest correlations were obtained for the relationship between a variety's initial shoot biomass and change in fresh shoot biomass $(r=0.974)$, initial fresh biomass and change in dry shoot biomass $(r=0.968)$, and initial total fresh biomass and change in total fresh biomass $(r=0.960)$. Initial dry root biomass was correlated strongly with changes in dry total biomass $(r=0.952)$ while initial dry root biomass was correlated with changes in dry shoot biomass after 21 days of moisture stress $(r=0.936)$.

The strongest correlation was obtained for the positive relationship between initial dry root biomass and changes in dry root biomass after 28 days of soil moisture deficit stress $(r=964)$, followed by the negative relationship between initial dry root biomass and changes in dry shoot biomass $(r=-0.904)$.

The results indicated that initial root biomass was negatively correlated with changes in total fresh and dry biomass of young coffee $(r>0.60$, Table 7) after both 21 and 28 days of soil moisture deficit stress, compared to initial shoot biomass which had weak correlation to both fresh and dry total biomass $(r<0.5)$.

\section{Discussion}

The absence of significance differences in initial root shoot and total biomass indicates that no coffee variety was significantly superior in biomass before soil moisture deficit stress. This confirms that under optimal conditions there are no morphological differences and yield differences between some of the coffee varieties tested in varietal trials [31]. It has however been established that significant morphological and physiological differences can occur between varieties due to different soil fertility and environmental factors $[32,33]$ meaning that when conditions are similar, there may not be any differences in common coffee varieties such as the ones used in this study.

Exposing the varieties to soil moisture stress for 21 and 28 days significantly affected fresh and dry biomass indicating that the growth performance of coffee varieties is significantly affected by soil moisture deficit stress. This confirms that drought stress has significant effect on morphological and other growth characteristics of coffee plants [23-25]. For most of the varieties there was a reduction in fresh biomass and a slow buildup of dry biomass during period of soil moisture deficit stress.

Reduction in fresh biomass could largely be due to the loss of water which considerably contributes to the fresh biomass of the coffee plants. This water is important in maintaining tissue elasticity in plants and its loss is evident in the morphological characteristics of plants such as wilting and leaf folding $[24,26]$. Whether the large losses in fresh shoot biomass in all varieties after 28 days of drought stress are a consequence of or a defense mechanism against drought stress is not certain. However, it is known that, in the early stages of soil moisture deficit, a plant would seek to maintain a constant rate of carbon assimilation which is achieved by reduction of leaf area, shedding other leaves, and/or other mechanisms that limit transpiration losses [21,23].

CR95 had positive changes in root biomass after 21 and 28 days of soil moisture stress indicating that the root system is an integral part of its tolerance to soil moisture deficit stress. This is because its fresh and dry shoot biomass decreased due to soil moisture stress but its root biomass maintained a positive development. This supports the fact that the root system of a variety or a crop species is an important aspect in drought tolerance $[4,21,24]$. This is largely because a deeper and wide reaching root system in drought tolerant varieties is able to source more water for a longer time for the plant's functioning. The findings that heavier root biomass in CR95 contributes significantly to its drought tolerance corroborate the conclusion by Ramos and Carvalho [34] that drought tolerance in coffee is associated with more root biomass. In as much as this is the case, breeding for root biomass (and associated features such as root length) in coffee presents many challenges given the large environmental and local influences on root systems and very complex inheritance of root characteristics in coffee $[4,23]$.

Unlike the initial biomass in which varieties were not significantly different, soil moisture stress resulted in significant differences between varieties in dry root biomass and total dry biomass after 21 days, and fresh root biomass, dry root biomass, dry shoot biomass, total fresh, and dry biomass after 28 days of soil moisture stress. In all these cases, CR95 showed that it was the most resilient variety because it had significantly more biomass and positive change in biomass after the soil moisture stress period.

Coffee plants demonstrated differences in responding to moisture availability after drought stress because of the differences in incremental biomass accumulations after both 21 and 28 days of soil moisture deficit stress. Thus, some 
TABLE 7: Pearson correlation coefficients $(r)$ between initial biomass of some coffee physiological variables and changes in mass of varieties after stress.

\begin{tabular}{|c|c|c|c|c|c|}
\hline \multirow{2}{*}{ Variable's initial biomass } & \multirow{2}{*}{ Variable responding after stress } & \multicolumn{2}{|c|}{21 days } & \multicolumn{2}{|c|}{28 days } \\
\hline & & Fresh & Dry & Fresh & Dry \\
\hline Fresh root & \multirow{2}{*}{ Roots } & 0.855 & 0.788 & 0.936 & 0.81 \\
\hline Dry root & & 0.657 & 0.597 & 0.968 & 0.964 \\
\hline Fresh shoots & \multirow{2}{*}{ Shoots } & 0.974 & 0.784 & -0.666 & 0.736 \\
\hline Dry shoots & & 0.968 & 0.772 & -0.666 & 0.726 \\
\hline Fresh total & \multirow{2}{*}{ Total } & 0.960 & 0.827 & 0.440 & 0.766 \\
\hline Dry total & & 0.914 & 0.872 & 0.550 & 0.835 \\
\hline Fresh root & \multirow{2}{*}{ Shoots } & -0.818 & -0.889 & 0.394 & -0.844 \\
\hline Dry roots & & -0.790 & -0.936 & 0.300 & -0.904 \\
\hline Fresh root & \multirow{2}{*}{ Total } & -0.83 & -0.912 & -0.625 & -0.827 \\
\hline Dry root & & -0.797 & -0.952 & -0.718 & -0.889 \\
\hline Fresh shoots & \multirow{2}{*}{ Total } & 0.265 & 0.293 & 0.290 & 0.385 \\
\hline Dry shoots & & 0.330 & 0.364 & 0.338 & 0.450 \\
\hline
\end{tabular}

varieties grow faster than others after a stress period [25]. This is partly explained by observations that photosynthate allocation is altered during period of drought stress and during recovery period the normal growth functioning is restored enabling the plant to return to its normal state $[21,23]$. What then makes differences is the quickness in which crop varieties trigger this mechanism depending on their genetic and physiological thresholds. However, some studies did not confirm this process in some varieties [24]. In terms of recovery from soil moisture stress, varieties were not consistent between recovering from 21 days and 28 days of soil moisture deficit stress signifying that the one week between these two periods is important during plant distress.

The general observation from this study is that variety CR95 is more drought tolerant than the rest of the varieties which were not significantly different from each other. This tolerance is both manifested and explained by superior root, shoot, and total fresh and dry biomass. These findings confirm the field observations that varieties with dense crowns (and thus more biomass) have lower boundary layer conductance which makes them better able to delay dehydration than those with open crowns [23]. Resultantly, densely crowned varieties are able to maintain productivity under water limiting environments and also require less irrigation for successful cropping.

It was observed that only initial fresh and dry root biomass was negatively correlated with change in biomass after physiological stress, while the rest of the factors had a positive correlation. This indicates that a coffee variety which has high root biomass is likely to withstand soil moisture deficit stress better than those with less root biomass or more shoot biomass. The fact that the other variables had a positive correlation to changes in biomass after stress shows that fresh and dry shoot biomass do not contribute to long term resilience of a variety as they are quickly lost when the plant is under stress. This is especially so for fresh shoot mass which is dominated by tissue water content [16].

Although characteristics that result in drought stress tolerance such as root and shoot biomass are positively correlated with productivity in coffee [34], selection for drought resistance through a variety's behavioral traits and assuming that this automatically equates to improved yield by that variety under stress may be a very shallow approach bound to result in negative consequences [35]. This is because potential yield in coffee may be negatively correlated with some of the drought-adaptive traits and thus adaptability may reduce economic yield. Regardless to this fact, as pointed out by DaMatta [23] drought prone coffee farms are associated with low input systems and as such varieties that have better survival and yield stability under drought stress are of much greater value than those with greater yield potential under optimal conditions but cannot survive or perform under limiting environments.

\section{Conclusions}

The coffee variety CR95 demonstrated that it is drought tolerant compared to SL28, Cat129, and Cat128 owing to its superior biomass accumulation. However, once CR95 has reached critical levels of wilting, it requires more time to recover. Cat129 exhibited better ability to recover from periods of soil moisture stress. It was therefore concluded that physiological and molecular characteristics responsible for delaying wilting in varieties are different from those responsible for recovery. Field screening may be required to confirm the performance of coffee varieties under field conditions and the relationship between the physiological factors such as girth, branching, and flowering to tolerance. In addition more work looking at biochemical response, photosynthetic ability, evapotranspiration rates, and other attributes of these coffee varieties under drought stress will provide important information. An understanding of drought tolerance in coffee at a molecular level is also required. This study provides important information into selection of varieties for drought tolerance for use in the coffee sector. However, a holistic approach to variety selection that incorporates drought, disease, pest, and frost tolerance may provide a stronger basis 
for variety selection for broad recommendations to farmers and crop breeders.

\section{Conflict of Interests}

The authors declare that there is no conflict of interests regarding the publication of this paper.

\section{Acknowledgments}

The authors want to acknowledge the contributions of staff in the Agronomy Section at Coffee Research Institute under the supervision of Mr. E Njeni for assisting in the management of the trial.

\section{References}

[1] ADBG, "Coffee production in Africa and the Global Market situation," Commodity Market Brief 1, 2010.

[2] P. Baker, J. Bentley, C. Charveriat, H. Dugne, T. Leftoy, and H. Munyua, "The coffee smallholder," in Coffee Futures: A Source Book of Some Critical Issues Confronting the Coffee Industries, P. Baker, Ed., p. 111, CABI-FEDERACAFE-USDAICO, Chinchiná, Colombia, 2001.

[3] J. Coste, Coffee: The Plant and the Product, Longman, New York, NY, USA, 1992.

[4] W. J. C. Logan and J. Biscoe, Coffee Handbook, Coffee Growers Association, Harare, Zimbabwe, 1987.

[5] T. S. Murphy, N. A. Phiri, K. Sreedharan, D. Kutywayo, and C. Chanika, "Integrated stem borer management in smallholder coffee farms in India, Malawi and Zimbabwe," Final Technical Report, 2008.

[6] A. Chemura, C. Mahoya, D. Kutywayo, and P. Chidoko, "The growth response of coffee plants to organic manure, inorganic fertilizers and integrated soil fertility management under different irrigation levels," in Proceedings of the RCZ International Research Symposium, vol. 1, HICC, Research Council of Zimbabwe, Harare, Zimbabwe, February 2013.

[7] D. Kutywayo, A. Chemura, W. Kusena, P. Chidoko, and C. Mahoya, "The impact of climate change on the potential distribution of agricultural pests: the case of the coffee white stem borer (Monochamus leuconotus P.) in Zimbabwe," PloS ONE, vol. 8, no. 8, Article ID e73432, 2013.

[8] M. Maestri, F. M. Da Matta, A. J. Regazzi, and R. S. Barros, "Water relations of coffee leaves (Coffea arabica and $C$. canephora) in response to drought," Journal of Horticultural Science, vol. 68, pp. 741-746, 1993.

[9] J. Haggar and K. Schepp, Coffee and Climate Change, University of Greenwich, London, UK, 2011.

[10] P. Baker and J. Haggar, "Global warming: effects on global coffee," in Proceedings of the Specialty Coffee Association of America Conference Handout (SCAA '07), p. 14, Long Beach, Calif, USA, 2007.

[11] International Coffee Organization, "Climate change and coffee," in Proceedings of the 103rd Session of International Coffee Organizatoin (ICO '09), p. 14, International Coffee Council, London, UK, 2009.

[12] P. Laderach, A. Jarvis, and J. Ramirez, "The impact of climate change in coffee-growing regions: the case of 10 municipalities in Nicaragua," CafeDirect/GTZ, GTZ, 2006.
[13] G. Schroth, P. Laderach, J. Dempewolf et al., "Towards a climate change adaptation strategy for coffee communities and ecosystems in the Sierra Madre de Chiapas, Mexico," Mitigation and Adaptation Strategies for Global Change, vol. 14, no. 7, pp. 605-625, 2009.

[14] C. Gay, F. Estrada, C. Conde, H. Eakin, and L. Villers, "Potential impacts of climate change on agriculture: a case of study of coffee production in Veracruz, Mexico," Climatic Change, vol. 79, no. 3-4, pp. 259-288, 2006.

[15] R. Ghini, W. Bettiol, and E. Hamada, "Diseases in tropical and plantation crops as affected by climate changes: current knowledge and perspectives," Plant Pathology, vol. 60, no. 1, pp. 122-132, 2011.

[16] S. G. Tesfaye, M. R. Ismail, H. Kausar, M. Marziah, and M. F. Ramlan, "Plant water relations, crop yield and quality of arabica coffee (Coffea arabica) as affected by supplemental deficitirrigation," International Journal of Agriculture \& Biology, vol. 15, pp. 665-672, 2013.

[17] B. M. Gichimu, Arabica Coffee Breeding: Challenges Posed by Climate Change, Kampala, Uganda, 2013.

[18] M. P. Reynolds, D. Hays, and S. Chapman, "Breeding for adaptation to heat and drought stress," in Climate Change and Crop Production, M. P. Reynolds, Ed., pp. 71-92, CABI, Oxfordshire, UK, 2010.

[19] D. Kutywayo, V. Chingwara, C. Mahoya, A. Chemura, and J. Masaka, "The effect of different levels of irrigation water and nitrogen fertilizer on vegetative growth components and yield of coffee in Zimbabwe," Journal of Science and Technology MSU, vol. 2, pp. 45-54, 2010.

[20] A. Arendse and T. A. Crane, "Impacts of climate change on smallholder farmers in Africa and their adaptation strategies: what are the roles for research?" in Proceedings of the International Symposium and Consultation: Centro Internacional de Agricultura Tropical (CIAT '10), p. 29, Pan-Africa Bean Research Alliance (PABRA), Arusha, Tanzania, 2010.

[21] F. M. DaMatta, A. R. M. Chaves, H. A. Pinheiro, C. Ducatti, and M. E. Loureiro, "Drought tolerance of two field-grown clones of Coffea canephora," Plant Science, vol. 164, no. 1, pp. 111-117, 2003.

[22] F. R. C. F. César, S. N. Matsumoto, A. E. S. Viana, M. A. F. Santos, and J. A. Bonfim, "Leaf morphophysiology of coffee plants under different levels of light restriction," Coffee Science, vol. 5, no. 3, pp. 262-271, 2010.

[23] F. M. DaMatta, "Exploring drought tolerance in coffee: a physiological approach with some insights for plant breeding," Brazilian Journal of Plant Physiology, vol. 16, no. 1, pp. 1-6, 2004.

[24] P. C. Dias, W. L. Araujo, G. A. B. K. Moraes, R. S. Barros, and F. M. DaMatta, "Morphological and physiological responses of two coffee progenies to soil water availability," Journal of Plant Physiology, vol. 164, no. 12, pp. 1639-1647, 2007.

[25] M. Worku and T. Astatkie, "Dry matter partitioning and physiological responses of Coffea arabica varieties to soil moisture deficit stress at the seedling stage in Southwest Ethiopia," African Journal of Agricultural Research, vol. 5, no. 15, pp. $2066-$ 2072, 2010.

[26] N. C. Turner, "Further progress in crop water relations," Advances in Agronomy, vol. 58, pp. 293-338, 1997.

[27] S. Haffani, M. Mezni, and W. Chaibi, "Effect of drought on growth and chlorophyll content in three Vetch species," IOSR Journal of Agriculture and Veterinary Science, vol. 2, pp. 50-56, 2013.

[28] P. Chidoko, C. Mahoya, A. Chemura, and D. Kutywayo, "Evaluation of the efficacy of Lantana camara, Albizia versicolor 
and Allium sativum for the control of coffee leaf rust under laboratory conditions," in Proceedings of the 1st International Conference on Pesticidal Plants (ICPP '13), J. O. Ogendo, C. W. Lukhoba, P. K. Bett, and A. K. Machocho, Eds., ADAAPT Network, Nairobi, Kenya, 2013.

[29] A. Chemura, R. Madhlazi, and C. Mahoya, "Recycled coffee wastes as potential replacements of inorganic fertilizers for coffee production," in Proceedings of the 22nd International Conference on Coffee Science (ASIC '08), pp. 1197-1201, Campinas, Brazil, September 2008.

[30] R. Core Team, R: A Language and Environment for Statistical Computing, R Foundation for Statistical Computing, Vienna, Austria, 2013.

[31] DR\&SS, “Annual Summary Report Division of Crops Research," Tech. Rep., Department of Research \& Specialist Services, Harare, Zimbabwe, 2011.

[32] A. Chemura, C. Mahoya, and D. Kutywayo, "Effect of organic nursery media on germination and initial growth of coffee seedlings," in Proceedings of the 23rd Colloquium of the Association for Science and Information on Coffee (ASIC '10), p. 11, Bali, Indonesia, October 2010.

[33] P. Chidoko, An Assessment of Genetic Diversity in Zimbabwean Coffee Varieties Using Morphological Markers [MSc], University of Zimbabwe, Harare, Zimbabwe, 2012.

[34] R. L. S. Ramos and A. Carvalho, "Shoot and root evaluations on seedlings from Coffea genotypes," Bragantia, vol. 56, no. 1, pp. 59-68, 1997.

[35] A. Blum, "Drought resistance, water-use efficiency, and yield potential-are they compatible, dissonant, or mutually exclusive?" Australian Journal of Agricultural Research, vol. 56, no. 11, pp. 1159-1168, 2005. 


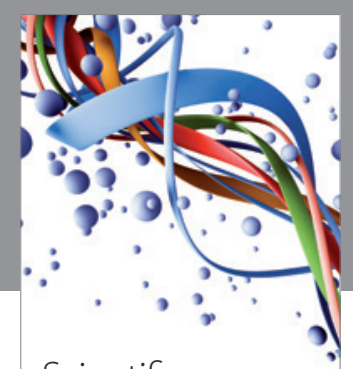

Scientifica
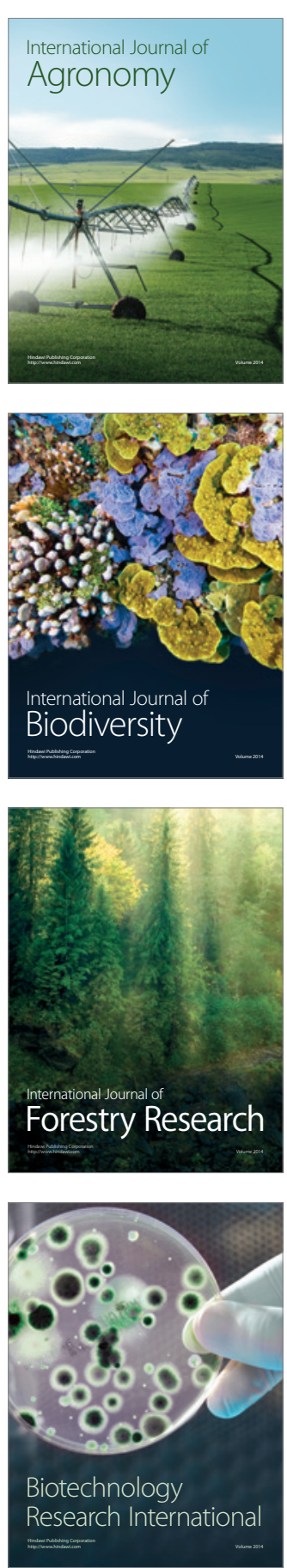
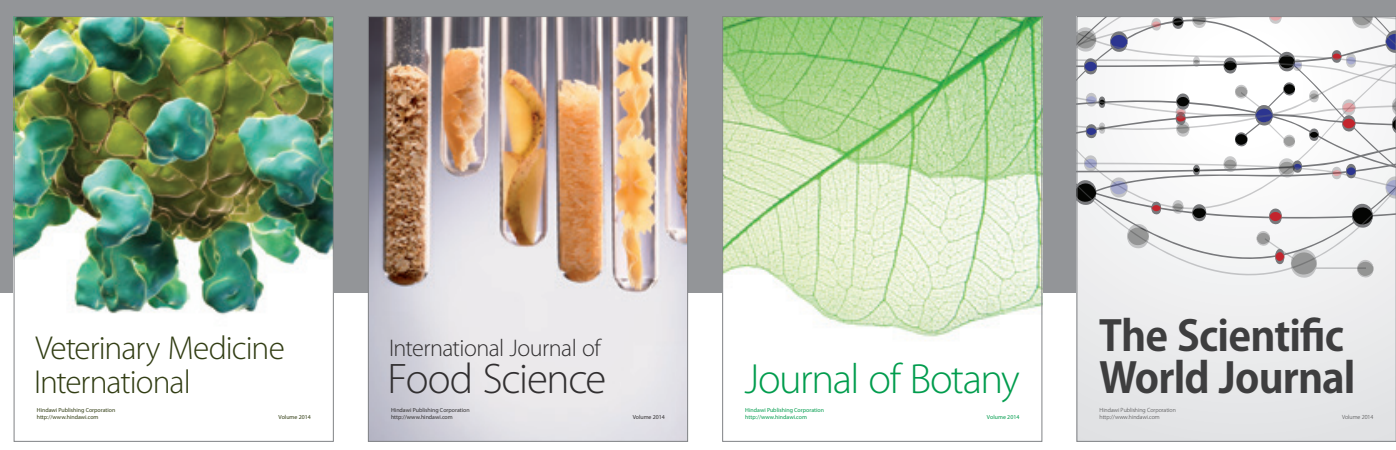

The Scientific World Journal
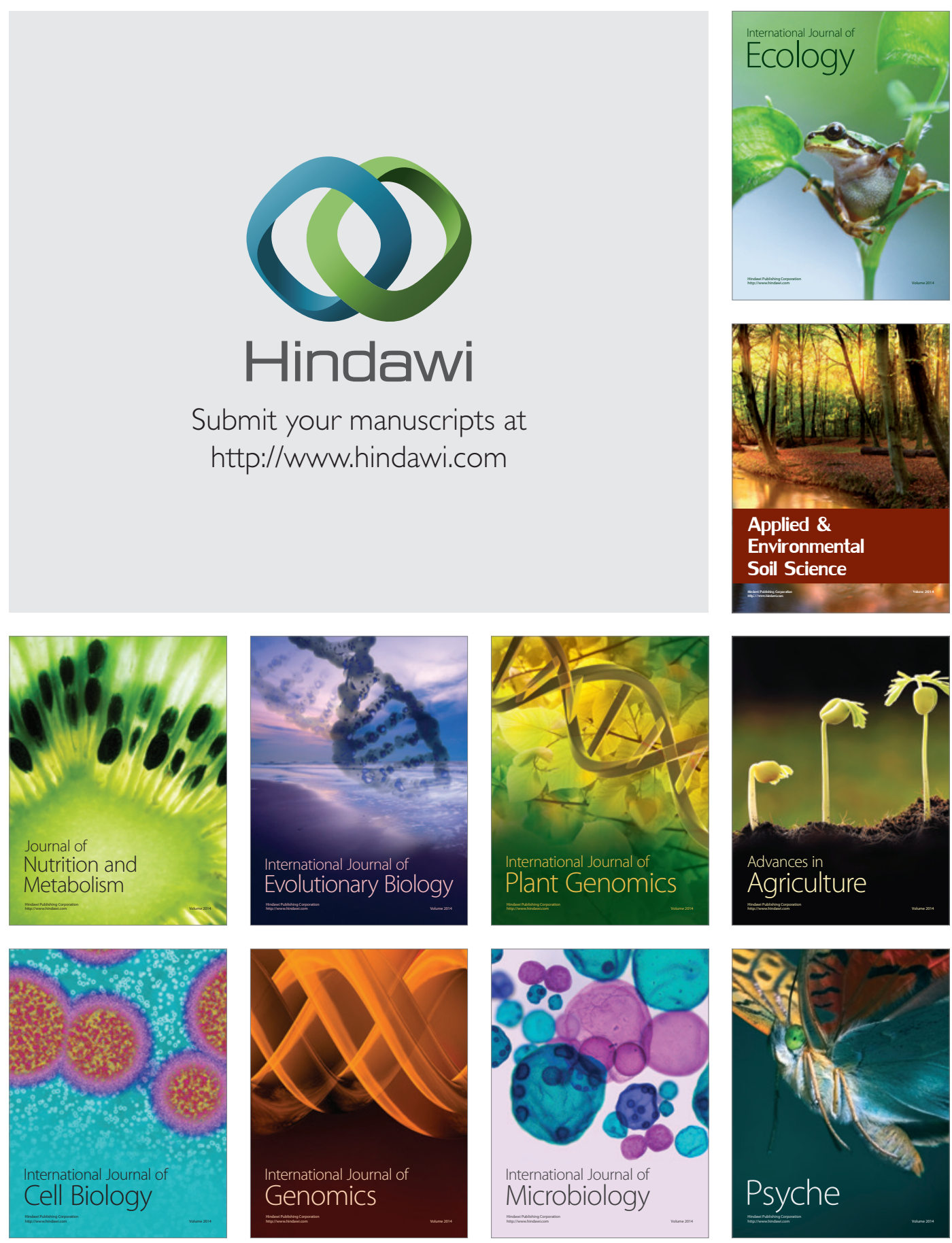